\title{
ESTIMATION OF SPATIAL VARIABILITY OF LIGNITE MINE DUMPING GROUND SOIL PROPERTIES USING CPTu RESULTS
}

\author{
IRENA BAGIŃSKA, MAREK KAWA \\ Wrocław University of Science and Technology, Wrocław, Poland, e-mail: marek.kawa@pwr.edu.pl
}

\author{
WOJCIECH JANECKI
}

Geosoft Sp. z o.o.

\begin{abstract}
The paper deals with application of CPTu test results for the probabilistic modeling of dumping grounds. The statistical measures use results from $42 \mathrm{CPT}$ test points located in the lignite mine dumping ground from the region of Central Europe. Both the tip resistance $q_{c}$ as well as local friction $f_{s}$ are tested. Based on the mean values and standard deviations of measured quantities the specific zones in the dumping site profile are distinguished. For three main zones standard deviations of linearly de-trended functions, distributions of normalized de-trended values for $q_{c}$ and $f_{s}$ are examined. Also the vertical scales of fluctuation for both measured quantities are estimated. The obtained result shows that lignite mine dumping site can be successfully described with the Random Field Theory. Additional use of $f_{s}$ values introduces supplementary statistical information.
\end{abstract}

Key words: Random Field Theory, fluctuation scale, CPTu testing, dumping ground soil

\section{INTRODUCTION}

Soils that form lignite mine dumping ground are a special case of anthropogenic soils. The original soil material comes from the layers of overburden covering the coal seam. The overburden is usually removed with the use of different types of excavators subsequently transported by the conveyor belts or trucks to the spoil site and dumped from various levels, with or without selection of the material (Buczko et al. 2001, Dmitruk 1965). As a result of this process, the obtained medium is heavily perturbed and devoid of natural soil structure. Consequently, observations in spoil heaps reveal relatively large spatial variability of most physical properties, rendering this material problematic for geotechnical design. Nevertheless, given that rehabilitation of dumpsites or their use for industrial purposes - while ensuring the stability of slopes - is an increasingly common task, there is a pressing need for an improved geotechnical design in this type of media. Developing methodology for geological studies, classification and description of dumping ground properties are all important and current geotechnical problems.
In the last decades, multiple methods based on probabilistic modeling of soil behavior have been developed. The main purpose of these methods is to estimate the risk associated with erecting different types of constructions on media with spatially variable properties. Recently, methods that combine MonteCarlo simulation with Random Field Theory have been of particular interest (RFEM Griffiths and Fenton 2001, Fenton and Griffiths 2003). These methods are still not widely used in the design practice, mostly due to their relatively high computational cost. However, their capacity to deal with media with high spatial variability makes them an adequate - and strongly grounded in the geological theory - choice for analysis of properties of the dumping grounds.

Simultaneously, the procedures allowing identification of the so-called fluctuation scales have also been developed. Fluctuation scales are basic parameters of the assumed correlation model, providing a convenient measurement of spatial variability of the field along specified direction. Since the number of observations necessary to identify fluctuation scales is significant, some studies (e.g., Lloret-Cabot et al. 2014) suggested using CPT and CPTu surveys for that purpose. 
In the current study, we investigated the scope of using CPTu results for determining statistical measures of the cone resistance $q_{c}$ and local friction $f_{s}$ in the lignite mine dumping ground. For that purpose $42 \mathrm{CPTu}$ tests were used. The mean values and standard deviations, as well as the probability distributions of the detrended quantities, were examined. Finally, we estimated vertical fluctuation scales of both properties generated respective random fields for several of their assumed values. We discuss our results in the light of the geotechnical methodology and eventual future application for describing properties of material that forms dumping ground.

\section{STATISTIC MEASURES OF A RANDOM FIELD}

According to Random Field Theory for the description of random variable in the field two sets of statistic information are needed, i.e., point value statistics as well as spatial correlation function. The point statistics can be fully described knowing the distribution (usually given in the form of probability density function). If the random variable under consideration is property of the soil, usually normal or lognormal distribution is assumed. Its parameters, i.e. mean and variance, can be easily identified using their commonly known unbiased estimators

$$
\hat{\mu}=\frac{1}{n} \sum_{i=1}^{n} X_{i}, \quad \hat{\sigma}^{2}=\frac{1}{n+1} \sum_{i=1}^{n}\left(X_{i}-\hat{\mu}\right)^{2},
$$

where $X_{i}$ is the estimated de-trend cone resistance or local friction value $\left(q_{c}\right.$ or $\left.f_{s}\right), k$ is the number of observations, $\hat{\mu}$ is mean value $\left(q_{c}\right.$ or $\left.f_{s}\right), \hat{\sigma}$ is standard deviation. When the normalized detrended $q_{c}$ or $f_{s}$ gives zero mean value $(\hat{\mu}=0)$ unit standard deviation $(\hat{\sigma}=1)$.

Extension of the characteristics of random variable at a point of the random field is carried out using correlation function which specifies correlation between points of the field. A typical correlation model is presented in Table 1. In geostatistics exponential function by Markov which can be expressed (in one dimension) as

$$
\rho(\tau)=\exp \left\{\frac{-2|\tau|}{\theta}\right\}
$$

is particularly popular (Fenton and Varmarcke 1990, Griffiths and Fenton 2001, Lloret-Cabot et al. 2014). This model has also been chosen in this paper.
Table 1. Correlation models

\begin{tabular}{|l|c|}
\hline \multicolumn{2}{|c|}{ Correlation model } \\
\hline Markov & $\rho(\tau)=\exp \left\{\frac{-2|\tau|}{\theta}\right\}$ \\
\hline Gaussian & $\rho(\tau)=\exp \left\{-\pi\left(\frac{|\tau|}{\theta}\right)^{2}\right\}$ \\
\hline Cosine exponential (CSX) & $\rho(\tau)=\exp \left\{-\frac{|\tau|)}{\theta}\right\} \cos \left(\frac{\tau}{\theta}\right)$ \\
\hline
\end{tabular}

The basic parameter for all correlation functions is the so-called fluctuation scale (Vanmarcke 1983), i.e., the length within which the correlation between two points is significant. Often, due to a small amount of data, the estimation of the fluctuation scale is not an easy task. This is not a problem in the case of CPTu test which is characterized by long data series.

A detailed algorithm for determining the value of fluctuation scale based on CPT data series has been presented in the work by Lloret-Cabot et al. (2014). According to that algorithm the value of vertical fluctuation scale is obtained by fitting the theoretical correlation model to the experimental correlation function. The latter can be estimated as

$$
\hat{\rho}\left(\tau_{j}\right)=\frac{1}{\hat{\sigma}^{2}(k-j)} \sum_{i=1}^{k-j}\left(X_{i}-\hat{\mu}\right)\left(X_{i=j}-\hat{\mu}\right)
$$

where $X_{i}$ is the estimated de-trend cone resistance or local friction value $\left(q_{c}\right.$ or $\left.f_{s}\right), k$ is the number of observations, $\tau_{j}$ corresponds to the depth of CPTU as a multiplication the number of observations $j=1,2, \ldots, k$, and adopted step $\tau_{j}=j \Delta \tau$.

Because it is assumed that the expected value and the variance of the random variable have the same value at all points of the field, the data showing a strong trend are subjected to de-trending (usually linear of quadratic, e.g., Uzielli et al. 2006, Pieczyńska-Kozłowska 2015 ) prior to using formula (3). The same methodology assuming a linear trend for obtained CPTu results, has been used in the present work.

The identical methodology can also be used for estimating the horizontal fluctuation scale value. It should be noticed that in the case of natural soils the value of horizontal fluctuation scale is usually several times greater than the vertical one (Kawa and Łydżba 2015) and for its estimation the data series from points with small horizontal lag are necessary.

\section{TEST AREA AND CPTu RESULTS}

Internal dumping site of lignite mine in Central Europe was chosen as an example of lignite mine dumping ground. All CPT tests were performed at the 
first bench of dumping site. The lowest layer of the dumping ground was made of selected spoil material with good compaction properties, with no control over the material in the layers located closer to the surface.

We analyzed $42 \mathrm{CPTu}$ tests conducted in the years 2005-2012 with the use of the electric piezocone. Arrangement of the test points is presented in Fig. 1. The distance between the adjacent test points ranged from approximately $12 \mathrm{~m}$ to approximately $580 \mathrm{~m}$.

Average values of $q_{c}$ and $f_{s}$ over all CPTu tests were calculated in order to elucidate characteristic zones in the profile of the dumping ground. After analysis of variation of both the mean and standard deviation (SD) of measured quantities (Fig. 2), the following zones have been distinguished in the soil mass.

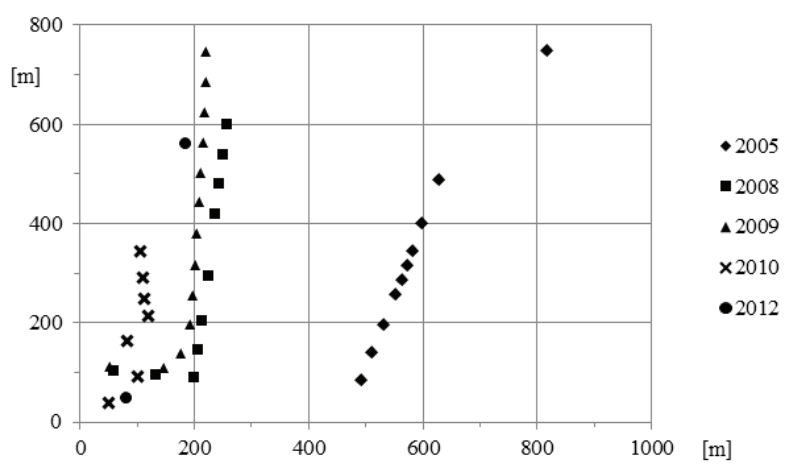

Fig. 1. Horizontal arrangement of test points
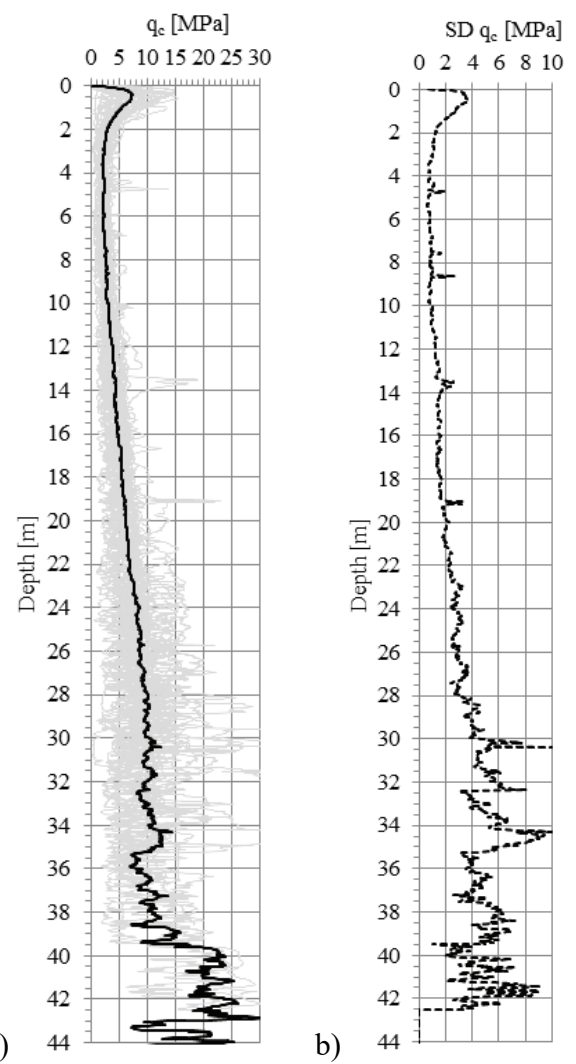

Zone I ( $0-3 \mathrm{~m}$ depth below ground level)

Surface zone characterized by a strong local increment in the registered $q_{c}$ and $f_{s}$ values. This zone was not included in the further analysis due to the possibility of uncontrolled factors occurring that may have influenced properties of the soil in that zone.

\section{Zone II (3-11 m d.b.g.l.)}

Dumping ground soil made of selected material. This zone was characterized by a very small increment in mean values of $q_{c}$ and $f_{s}$, as well as low SD values of $q_{c}$ and $f_{s}$, with little variance between them. DS $q_{c}<1$ (Table 2).

\section{Zone III (11-18 m d.b.g.l.)}

Dumping ground soil made of selected material. This zone was characterized by the mean values of $q_{c}$ and $f_{s}$ steadily increasing with depth, as well as greater and more variable values of SD of $q_{c}$ and $f_{s}$ than in the zone II. $1<$ DS $q_{c}<2$ (Table 2 ).

\section{Zone IV (18-25 m d.b.g.1.)}

Dumping ground soil made of selected material, mostly sand. That zone was characterized by the mean
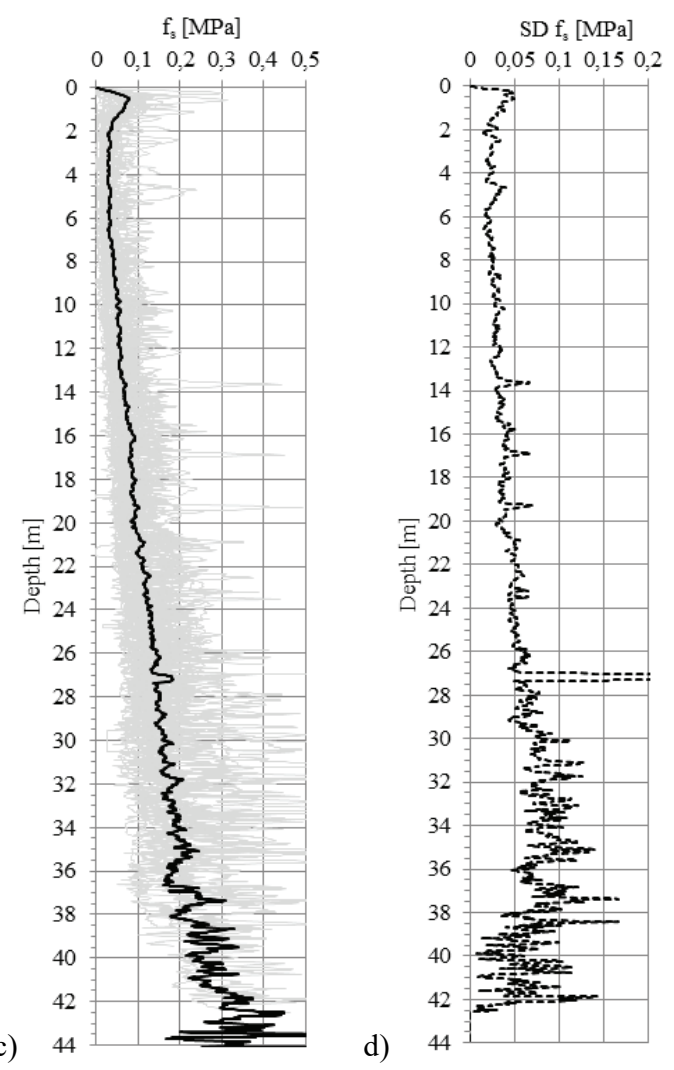

Fig. 2. (a) mean $q_{c}$ value; (b) SD of $q_{c}$ value; (c) mean $f_{s}$ value; (b) SD of $f_{s}$ value 
values of $q_{c}$ and $f_{s}$ steadily increasing with depth as well as greater and highly variable values of SD of $q_{c}$ and $f_{s}$. DS $q_{c}>2$ (Table 2).

\section{Zone V (below $25 \mathrm{~m}$ d.b.g.l.)}

This zone was omitted in further analysis due to a much smaller number of available data points and high values of SD of $q_{c}$.

Measures that characterize variability of parameters $q_{c}$ and $f_{s}$ based on 42 CPTU surveys for zones II, III and IV are presented in Table 2. Values of $q_{c}$ and $f_{s}$ increase with depth. Standard deviations of these parameters also increase with depth, i.e., the dispersion of values of $q_{c}$ and $f_{s}$ is increasing with depth for different CPT tests. Increase of standard deviation of $q_{c}$ vs. depth is uniform, as shown by very similar values of $\mathrm{CoV}$ (varying from $32.33 \%$ to $33.87 \%$ ).

Table 2. Properties of zones II, III and IV, referred to all $q_{c}$ and $f_{s}$ values

\begin{tabular}{|c|c|c|c|c|c|}
\hline \multirow{3}{*}{ Zone } & \multicolumn{5}{|c|}{ Features resulting from $q_{c}$} \\
\hline & \multirow{2}{*}{$\begin{array}{c}\text { Mean value } \\
\text { min-max } \\
{[\mathrm{MPa}]}\end{array}$} & \multicolumn{2}{|r|}{$\begin{array}{c}\mathrm{SD} \\
{[\mathrm{MPa}]}\end{array}$} & \multicolumn{2}{|r|}{$\begin{array}{l}\mathrm{CoV} \\
{[\%]}\end{array}$} \\
\hline & & mean & $\min -\max$ & mean & $\min -\max$ \\
\hline II & $2.079-3.477$ & 0.869 & $0.616-2.747$ & 33.87 & $25.41-88.16$ \\
\hline III & $3.369-5.611$ & 1.437 & $0.955-2.588$ & 32.33 & $23.55-57.61$ \\
\hline IV & $5.505-8.665$ & 2.306 & $1.429-3.413$ & 33.04 & $24.85-52.05$ \\
\hline \multirow{3}{*}{ Zone } & \multicolumn{5}{|c|}{ Features resulting from $f_{s}$} \\
\hline & \multirow{2}{*}{$\begin{array}{c}\text { Mean value } \\
\text { min-max } \\
{[\mathrm{MPa}]}\end{array}$} & \multicolumn{2}{|r|}{$\begin{array}{c}\mathrm{SD} \\
{[\mathrm{MPa}]}\end{array}$} & \multicolumn{2}{|r|}{$\begin{array}{l}\mathrm{CoV} \\
{[\%]} \\
\end{array}$} \\
\hline & & mean & $\min -\max$ & mean & $\min -\max$ \\
\hline II & $0.026-0.059$ & 0.025 & $0.016-0,039$ & 67.45 & $48.51-111.53$ \\
\hline III & $0.052-0.093$ & 0.035 & $0.022-0,068$ & 50,27 & 39.91-93.80 \\
\hline IV & $0.081-0.137$ & 0.045 & $0.028-0,071$ & 42.08 & 31.99-68.59 \\
\hline
\end{tabular}

Values of coefficient of variation $(\mathrm{CoV}) q_{c}$ estimated for soils considered referred to all measuring points (Table 2) are approximately two times higher than the same estimated for natural soils (based on the results presented by Uzielli at al. 2006). In the case of $f_{s}$ there are no relevant literature references.

Mean values of $q_{c}$ and $f_{s}$ calculated for zones II, III and IV are highly correlated. They can be estimated by linear equations with very high coefficients of determination (Fig. 3). For zone II $\mathrm{R}^{2}=0.84$, for zone III $\mathrm{R}^{2}=0.81$ and for zone IV $\mathrm{R}^{2}=0.85$.

To relate the investigated soil to the classifications applicable to natural soils, all CPTU results considered were entered to SBT nomogram (Robertson 2010). Mean values, split according to zones II, III and IV, generated a very compact group (Fig. 4a), suggestive of high uniformity of the soil material. This may be explained, among other things, by the fragmentation and mixing during the transport process (resulting in disappearance of the natural properties of soils, with concurrent emergence of new ones which are more uniform on the global scale). Robertson's nomogram refers to that "new soil" as sand mixtures; silty sand to sandy silt-SBT5.

Furthermore, for better characterization of the zones considered, an $\mathrm{I}_{\mathrm{SBT}}$ index (Robertson 1990) was calculated, according to the following equation

$$
\mathrm{I}_{\text {STВ }}=\sqrt{\left[3.47-\log \left(\frac{q_{c}}{p_{a}}\right)\right]^{2}+\left(\log R_{f}+1.22\right)^{2}} \text {. }
$$

Mean values of $\mathrm{I}_{\mathrm{SBT}}$ index calculated on the basis of mean $q_{c}$ and $f_{s}$ values vs. depth are presented in Fig. $4 \mathrm{~b}$. Characteristic values that describe its variability are summarized in Table 3. Obtained results indicate high

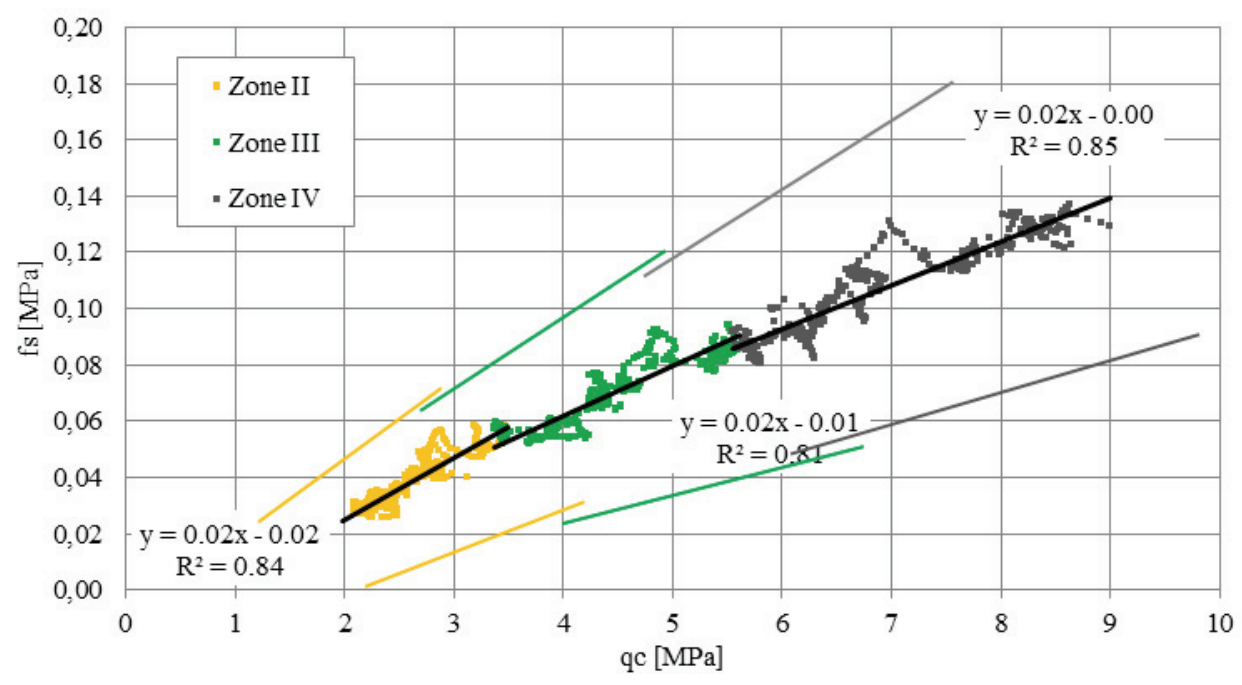

Fig. 3. Mean values of $q_{c}$ vs. mean values of $f_{s}$ 


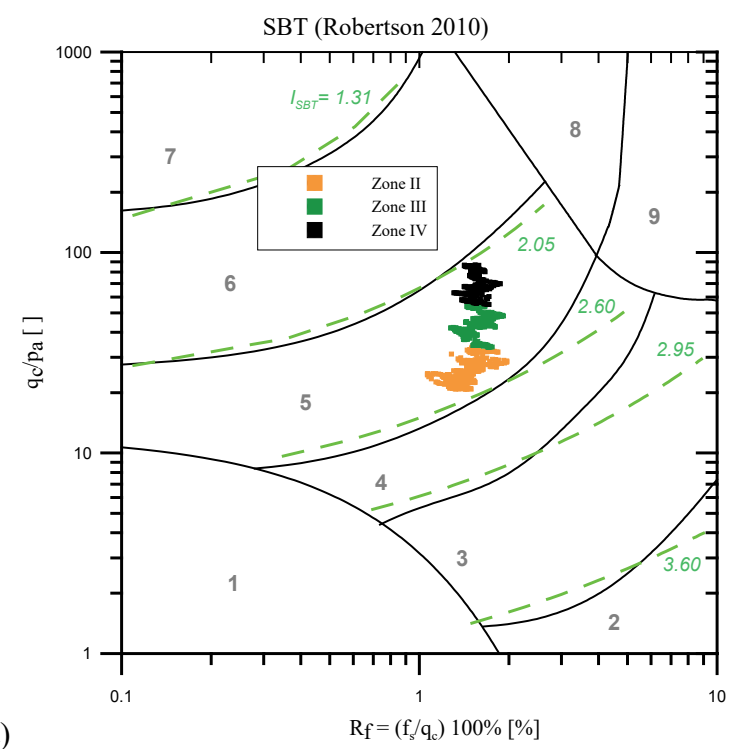

b)

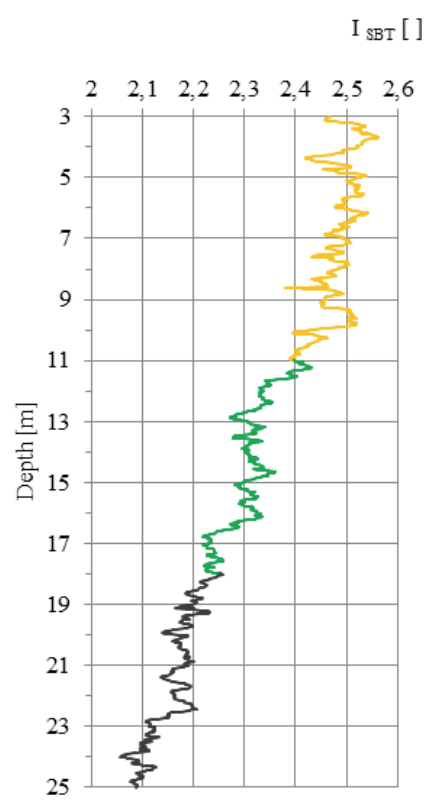

Fig. 4. (a) SBT by Robertson 2010; (b) I I $\mathrm{SBT}$ vs. depth

uniformity of investigated soil in vertical scale, however, the question about horizontal uniformity remains open.

Table 3. Variability of $\mathrm{I}_{\mathrm{SBT}}$ index

\begin{tabular}{|c|c|c|c|}
\hline Zone & $\begin{array}{c}\text { Mean value I } \\
{[]}\end{array}$ & $\begin{array}{c}\text { SD I }_{\text {SBT }} \\
{[]}\end{array}$ & $\begin{array}{c}\text { CoV I } \\
{[\%]}\end{array}$ \\
\hline II & 2.434 & 0.036 & 1.48 \\
\hline III & 2.325 & 0,072 & 3.09 \\
\hline IV & 2.171 & 0,083 & 3.81 \\
\hline
\end{tabular}

The value of CoV (Table 4) calculated for mean values of $q_{c}$ is almost constant. This confirms the stable trend of increasing mean value of $q_{c}$ vs. depth with simultaneous increase of standard deviation (SD). That relation is not visible for $f_{s}$ values, which mean values increase more rapidly than their SD.

Table 4. Mean values of $q_{c}$ in vertical scale for zones II, III and IV

\begin{tabular}{|c|c|c|c|c|c|c|}
\hline \multirow{2}{*}{ Zone } & \multicolumn{3}{|c|}{$q_{c}$} & \multicolumn{3}{c|}{$f_{s}$} \\
\cline { 2 - 8 } & $\begin{array}{c}\text { Mean value } \\
{[\mathrm{MPa}]}\end{array}$ & $\begin{array}{c}\text { SD } \\
{[\mathrm{MPa}]}\end{array}$ & $\begin{array}{c}\mathrm{CoV} \\
{[\%]}\end{array}$ & $\begin{array}{c}\text { Mean value } \\
{[\mathrm{MPa}]}\end{array}$ & $\begin{array}{c}\text { SD } \\
{[\mathrm{MPa}]}\end{array}$ & $\begin{array}{c}\text { CoV } \\
{[\%]}\end{array}$ \\
\hline II & 2.581 & 0.356 & 13.80 & 0.038 & 0.009 & 23.05 \\
\hline III & 4.489 & 0.622 & 13.85 & 0.070 & 0.012 & 17.09 \\
\hline IV & 6.926 & 0.921 & 13.30 & 0.107 & 0.016 & 14.48 \\
\hline
\end{tabular}

\section{DETERMINATION OF STATISTICAL MEASURES FOR THE DUMPSITE}

Determination of all the random field parameters has been performed for II, III and IV zones of the dumping ground. In the first stage of the analysis, from the values of $q_{c}$ and $f_{s}$ a linear trend has been subtracted (for each parameter, the trend has been determined separately). The obtained values $q_{c}$ and $f_{s}$, for all test points, and an average linear trend in the individual zones are shown in Figs. 5 and 6. As shown in the figures, the assumed linear trend corresponds to the data. In the case of $f_{s}$, however, one can see that much of the data are located on one of the diagrams. In the next step, for de-trended values, the standard deviation $\sigma_{\text {res }}$ has been determined and all the values have been normalized by dividing by the obtained value of $\sigma_{\text {res. }}$ Then, to determine the distribution of the random variable for the obtained normalized values, a histogram has been made. Histograms with the best fit of the standard distribution as well as the mean of the de-trended values, for each zone, for $q_{c}$ and $f_{s}$ are presented in Figs. 7 and 8 , respectively. As is shown in the drawings the detrended mean values for both $q_{c}$ and $f_{s}$ are close to zero and do not appear to have any higher level trends (e.g., quadratic). It appears that the normal distribution fits well into the histogram of $q_{c}$, and in the case of $f_{s}$, even though the fit is satisfactory, resulting histogram is clearly asymmetric, indicating different distribution of measured $f_{s}$ values. 

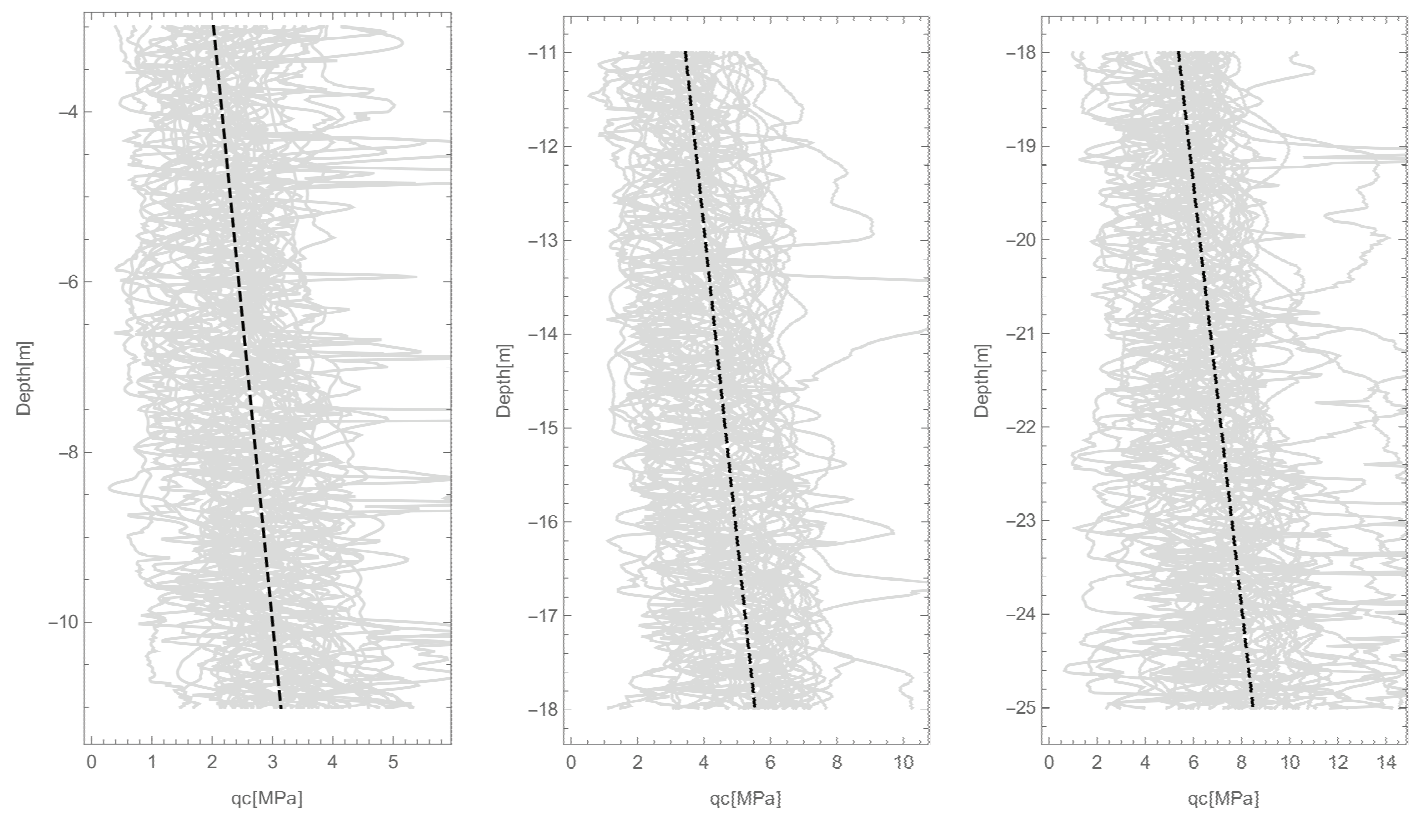

Fig. 5. $q_{c}$ values for all tests (gray) with mean linear trend line (dashed) for zones II, III and IV
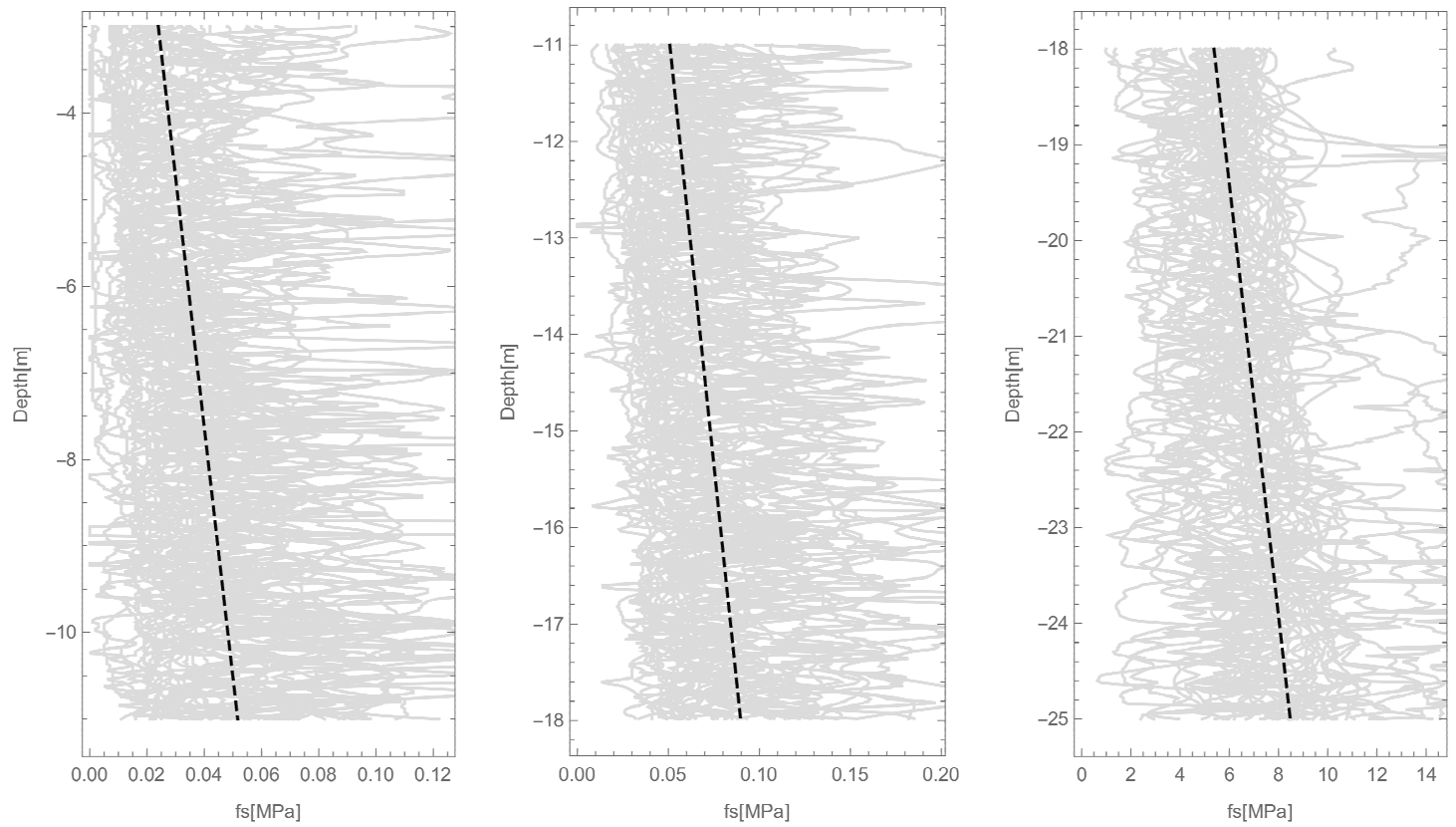

Fig. 6. $f_{c}$ values for all tests (gray) with mean linear trend line (dashed) for zones II, III and IV

Finally, for de-trended normalized values correlation function (3) has been estimated. A few different correlation models have been analyzed (Table 1).

As the most suitable, the Markov model has been selected. For that model, the vertical scale of fluctuation has been identified by its fitting in the estimated correlation function. Correlation functions and Markov model for all zones for $q_{c}$ and $f_{s}$ are shown in Figs. 9 and 10 , respectively. Although it seems that for both $q_{c}$ and $f_{s}$ the correlation model has been chosen correctly, one can see that in the same zone different scale of fluctuations for $q_{c}$ and $f_{s}$ has been obtained. This difference can have several causes. Partially, it may be due to the measurement or statistical errors. It may also be due to the fact that when measuring both $q_{c}$ and $f_{s}$ probably some spatial averaging of soil properties over area of failure mechanism occurs, which is different for $q_{c}$ and $f_{s}$.

Due to the large distances between the test points no attempt has been made to determine the horizontal fluctuation scale. The problem with a large number of closely spaced points needed to determine 

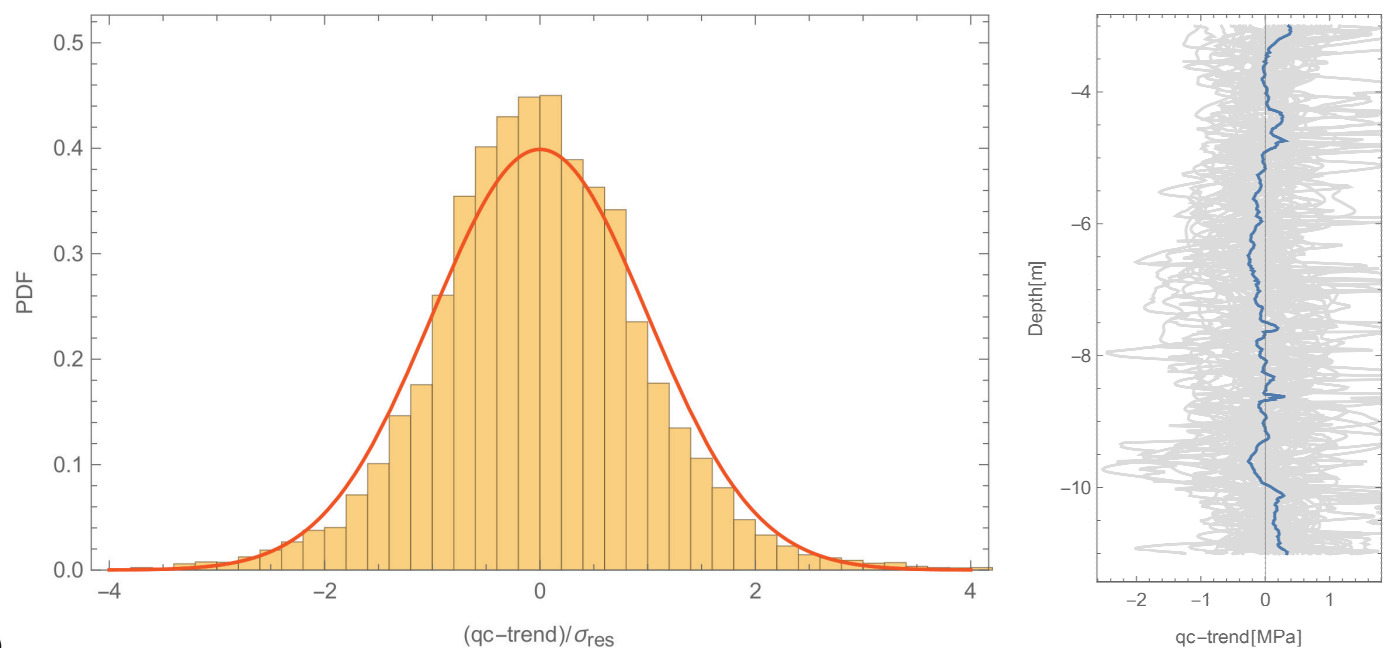

a)

(qc-trend) $/ \sigma_{\text {res }}$

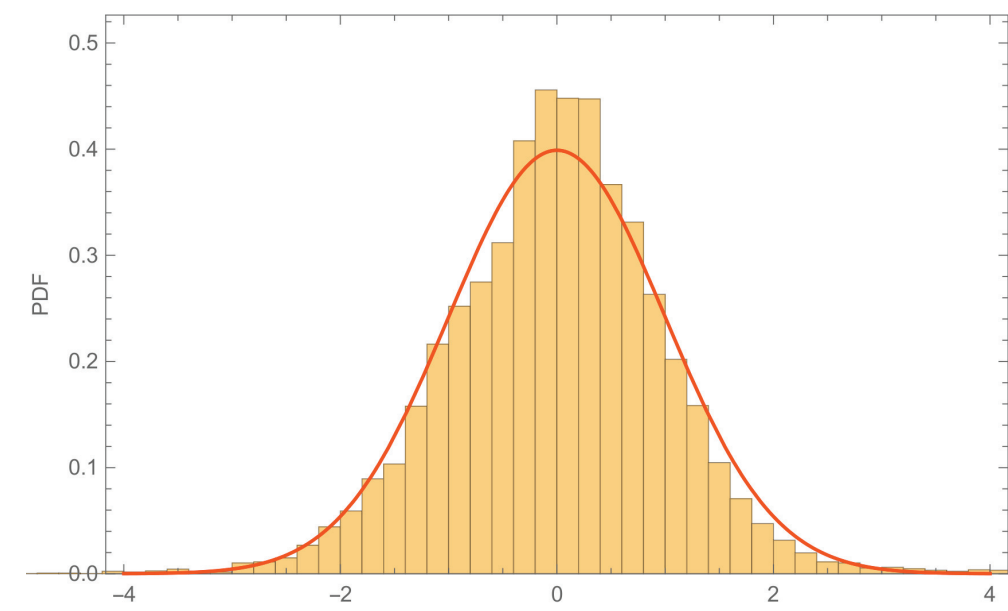

b)

(qc-trend) $/ \sigma_{\text {res }}$
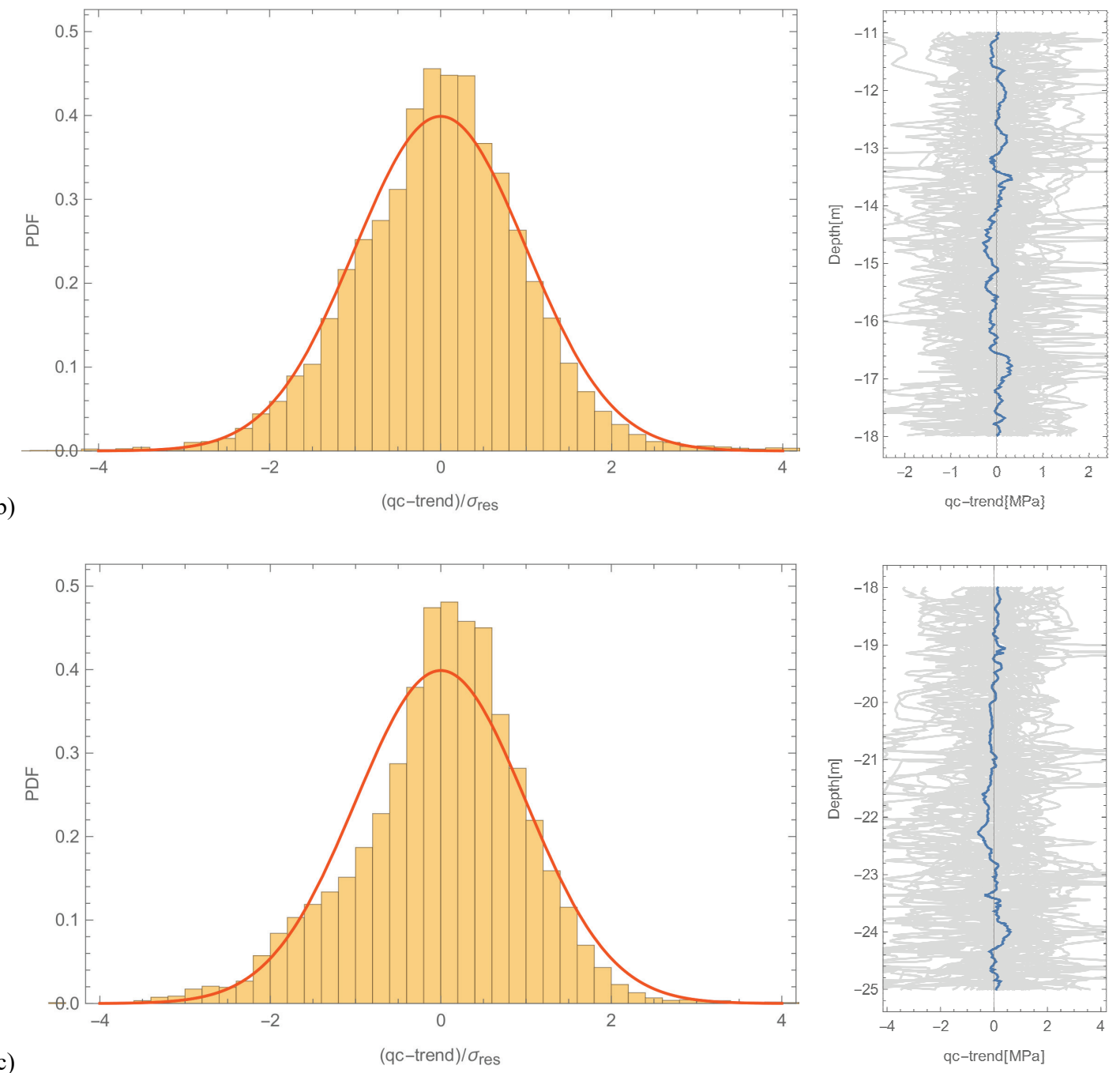

c)

Fig. 7. Left: histogram of de-ternded normalized $q_{c}$ values with normal distribution; right: variability of mean de-trended $q_{c}$ values: (a) zone II, (b) zone III, (c) zone IV

the horizontal scale of the fluctuations is well known (e.g., Vessia et al. 2009). If some assumptions should be made it seems intuitive (taking into account the way of forming the dumping ground) that the value of horizontal fluctuation scale should be probably similar to the vertical one. Verification of this hypothesis requires further targeted research. 

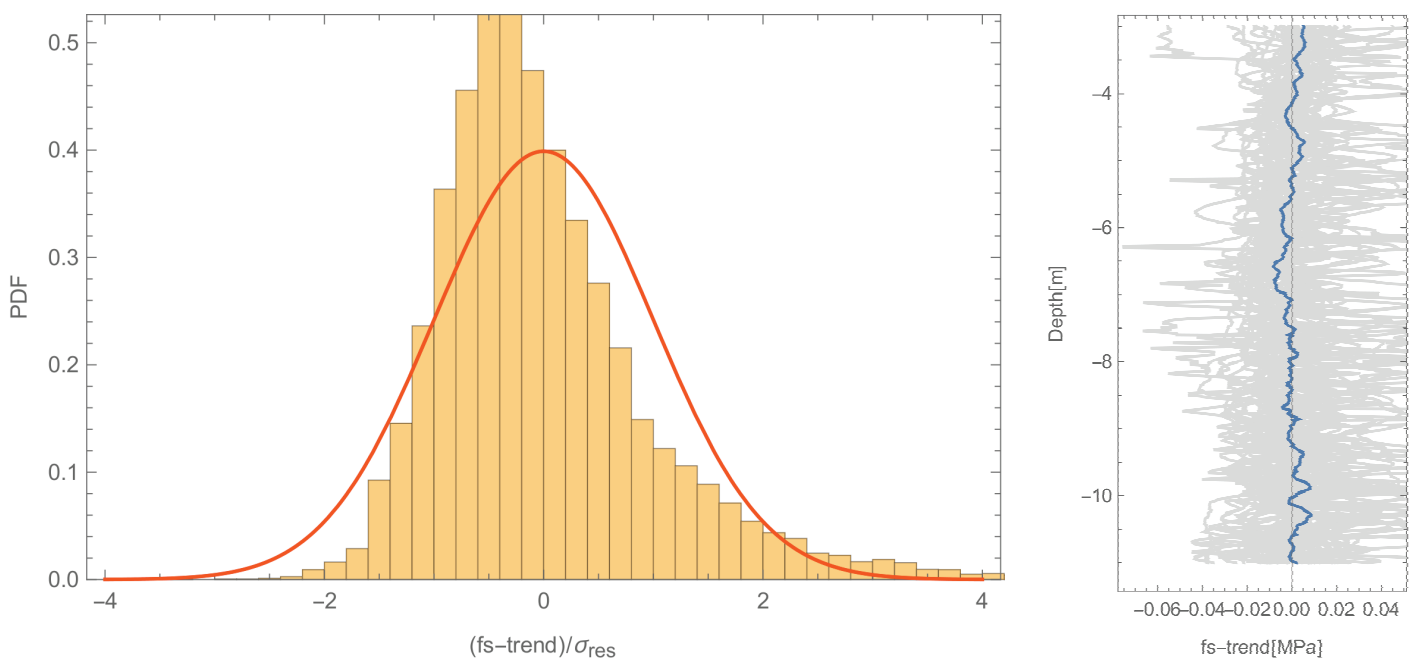

a)

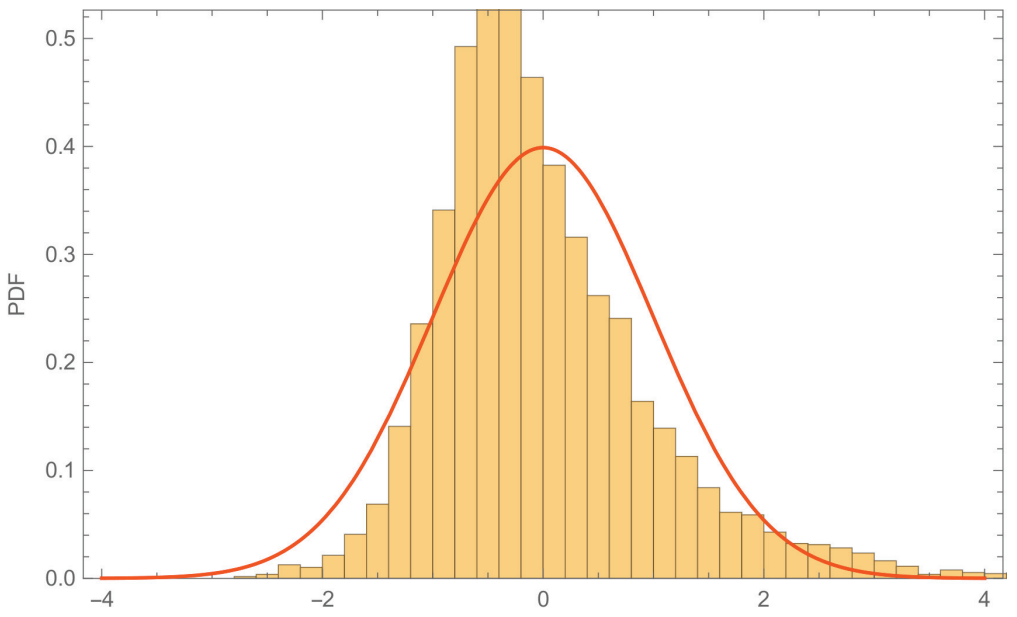

b)

(fs-trend) $/ \sigma_{\text {res }}$

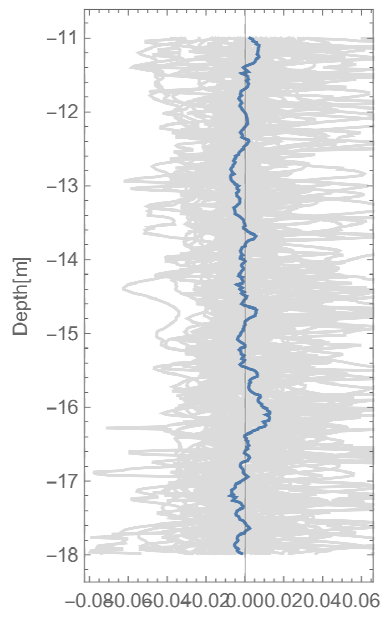

fs-trend[MPa]
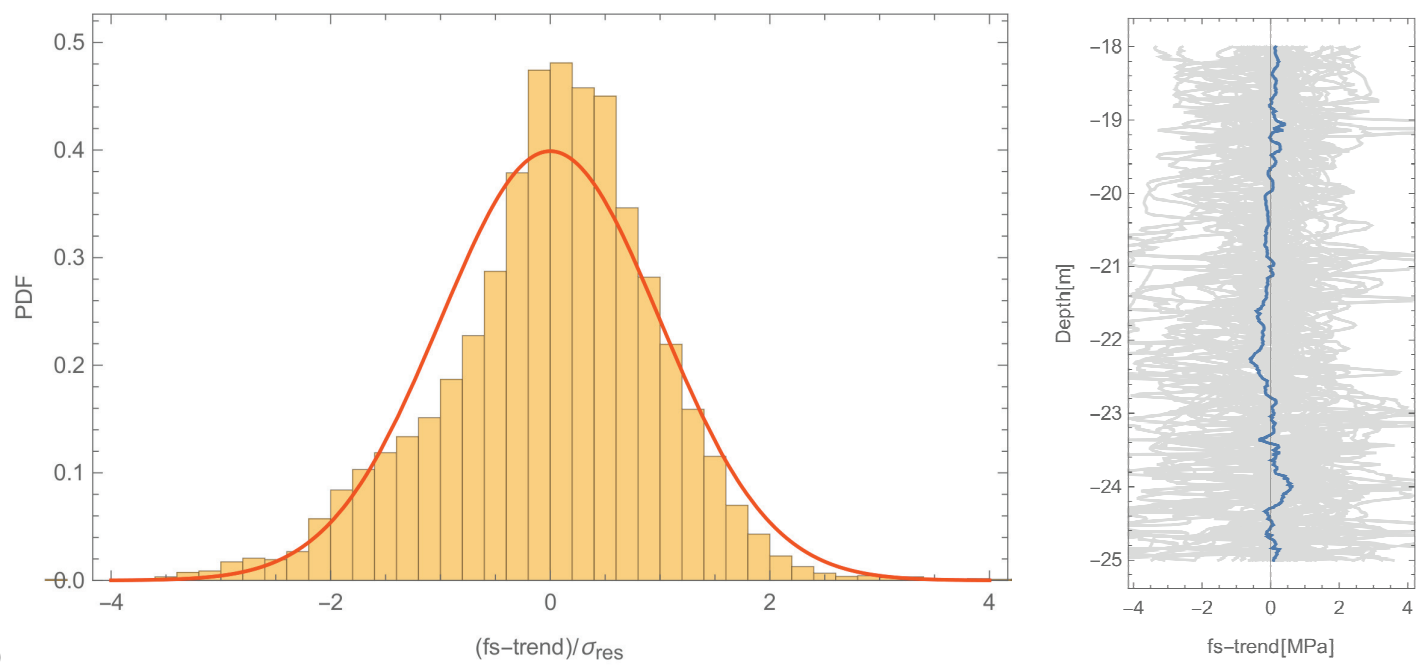

Fig. 8. Left: histogram of de-ternded normalized $f_{s}$ values with normal distribution; right: variability of mean de-trended $f_{s}$ values: (a) zone II, (b) zone III, (c) zone IV 


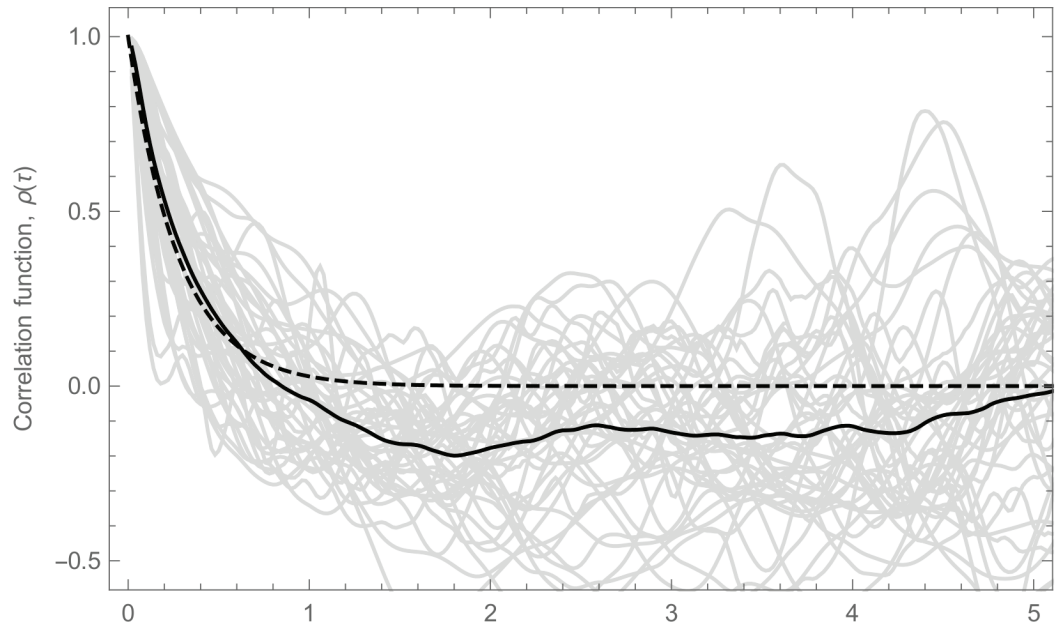

a)

Vertical Lag $[\mathrm{m}]$

$\theta=0.56$

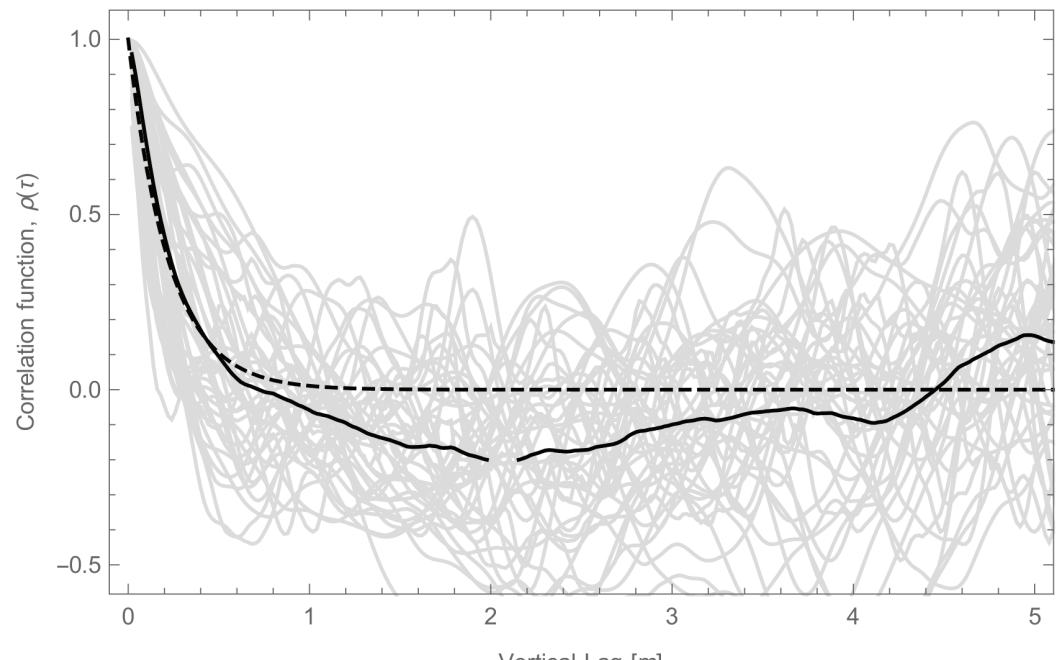

b)

Vertical Lag $[\mathrm{m}]$

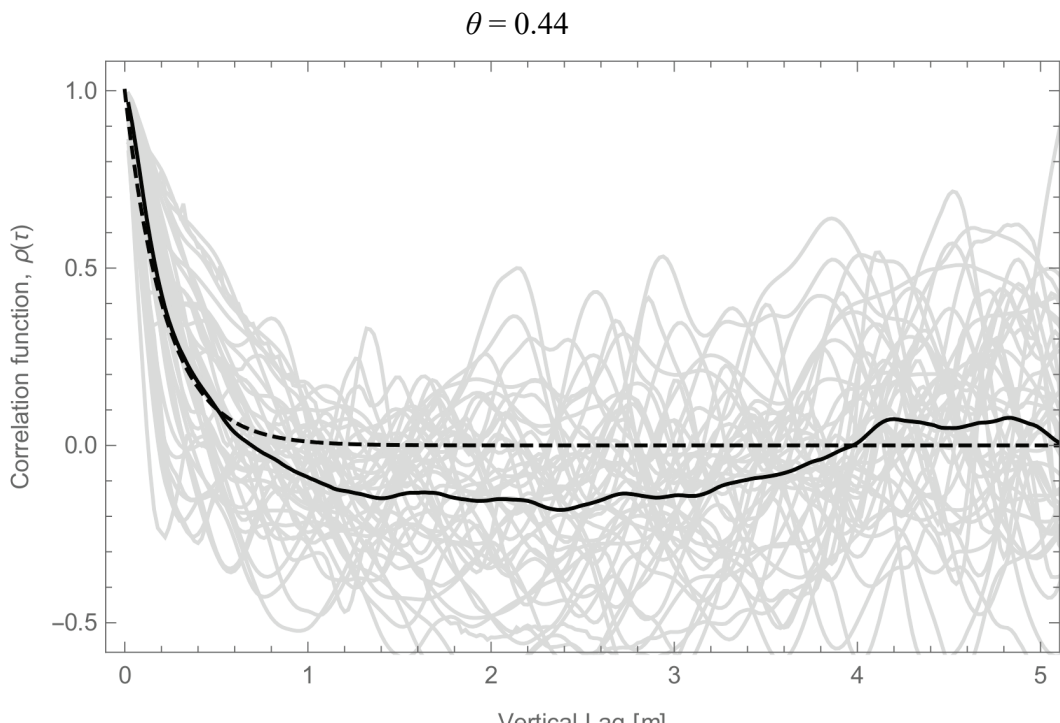

c)

$\theta=0.44$

Fig. 9. Estimated correlation functions for de-trended normalized $q_{c}$ values (grey), their mean (black) and best fit of Markov model (dashed): (a) zone II, (b) zone III, (c) zone IV. Obtained values of flcutuaction scale $\theta$ specified in the figure 


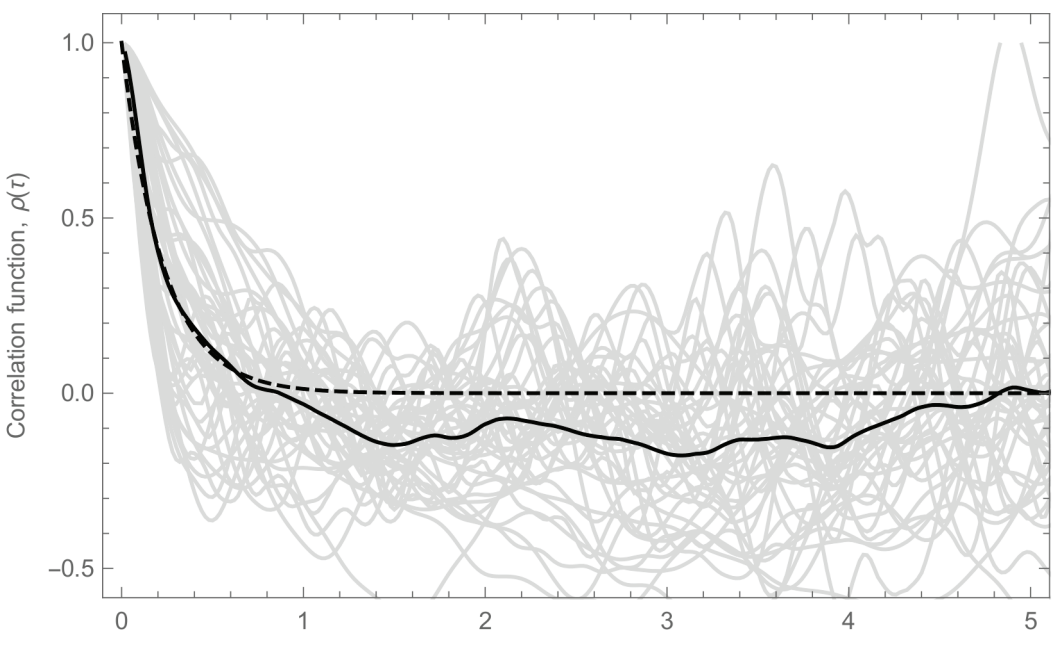

a)

Vertical Lag $[\mathrm{m}]$

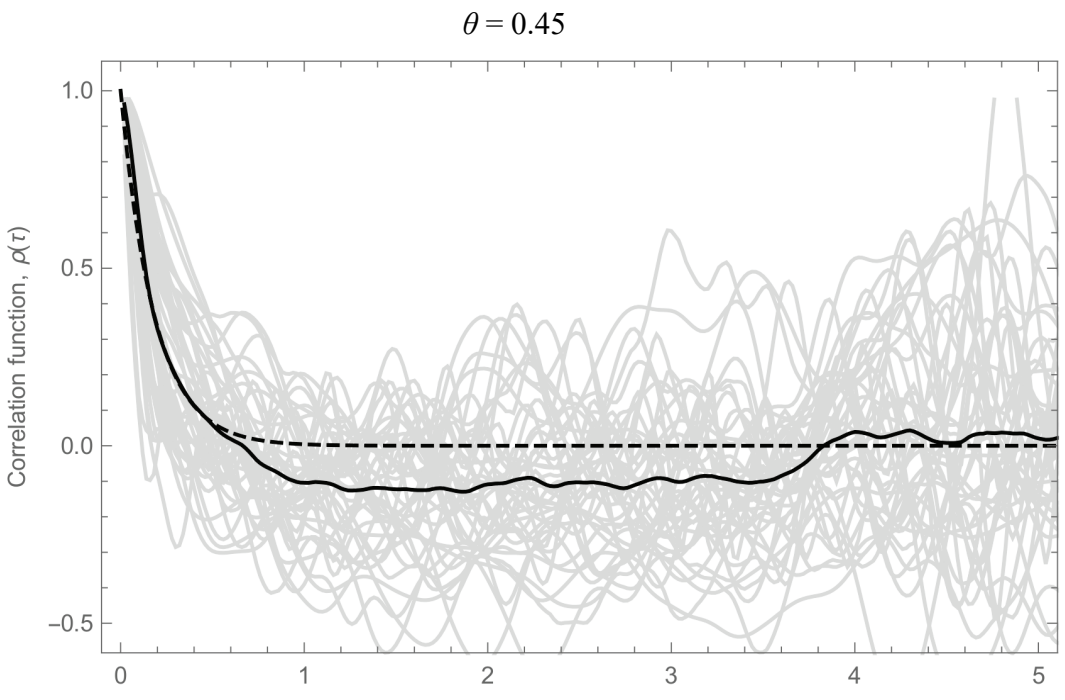

b)

Vertical Lag $[\mathrm{m}]$

$$
\theta=0.36
$$

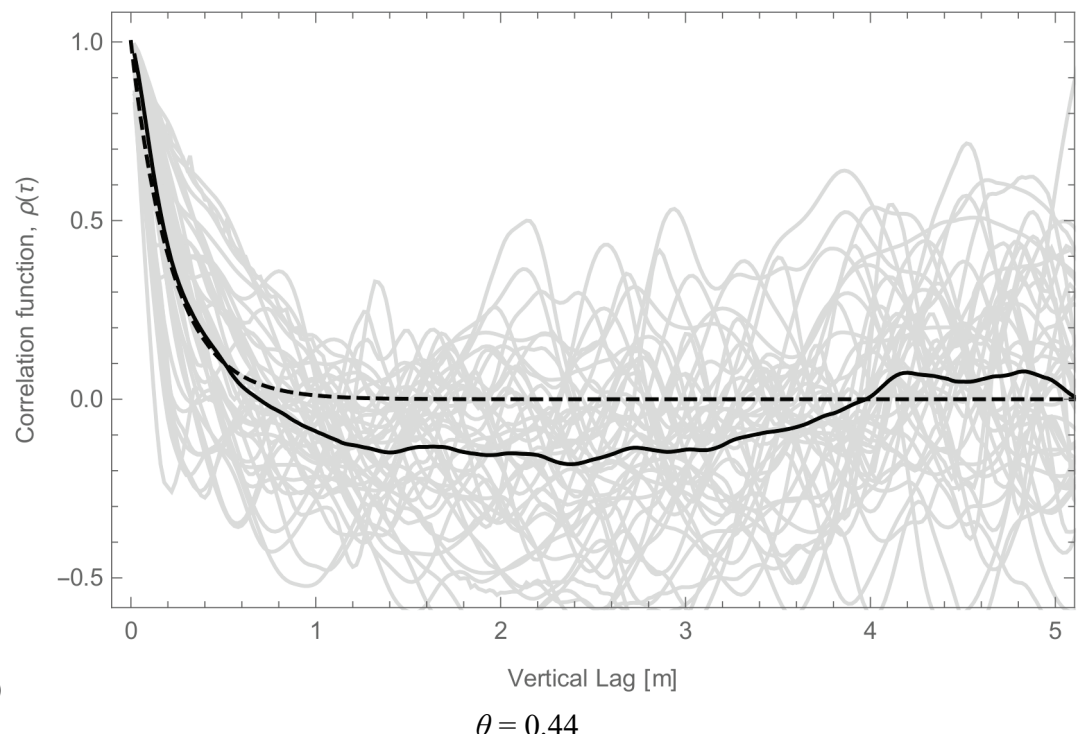

Fig. 10. Estimated correlation functions for de-trended normalized $f_{s}$ values (grey), their mean (black) and best fit of Markov model (dashed): (a) zone II, (b) zone III, (c) zone IV. Obtained values of flcutuaction scale $\theta$ specified in the figure 


\section{CONCLUSIONS}

We used the CPTu results from lignite mine spoils dump site to obtain statistical measures of variability of dumping ground soil strength properties. The main parameters of our interest included the mean, variance as well as distribution for $q_{c}$ and $f_{s}$. Furthermore, we estimated the vertical scale of fluctuation for both properties. The conclusions of our work are presented below.

(i) The lignite main dumping ground soil is a medium characterized by large spatial variability of most physical properties. This fact justifies the use of probabilistic modeling based on Random Field Theory for its analysis. The well-known disadvantages of this approach are the significant number of observations necessary for estimating the scale of fluctuation, as well as the high computational cost. While the latter remains problematic, the former can be solved using CPTu results. Since these results are already available from monitoring programs for many dumpsites, applying the presented methodology seems feasible.

(ii) The obtained values of the horizontal fluctuation scale are high in relation to the natural soil (see, e.g., Uzielli et al. 2006). This is consistent with our predictions: during formation of the dumpsite, specific parts of the material are distributed along a relatively large space and the mixed material is subjected to local homogenization.

(iii) When determining the properties of the random field using CPTu test, most studies rely solely on the tip resistance $q_{c}$. In our opinion, use of local friction - usually available for CPTU - can introduce additional information and significantly reduce the statistical error.

(iv) It is easy to notice that the examined probability distributions for $q_{c}$ and $f_{s}$ are qualitatively different. While for $q_{c}$ normal distribution corresponds very well to the results so far, this is not the case for $f_{s}$. The shape of the histogram may suggest that the random field of $f_{s}$ is better modelled with an asymmetric distribution. This hypothesis needs to be tested.

Future research should clarify several outstanding issues. These include:

(i) Vertical fluctuation scales obtained for $q_{c}$ are $f_{s}$ have different values. Although the difference is not substantial and might have arisen for a number of reasons (e.g., diversified origin of soils along the bench investigated), it may be due to different range of failure mechanism during meas- urement of $q_{c}$ and $f_{s}$. This could suggest that fluctuation scales obtained from CPTu results are not universal. Their use, e.g., to generate fields of cohesion and internal friction in determining the carrying capacity of the foundation, should be done with caution.

(ii) Due to the considerable distance between the test points, no attempt was made to estimate the horizontal fluctuation scale. It is worth noting that although, in the case of natural soils, the horizontal fluctuation scale is usually much greater than the vertical one, in the case of dump ground soils these scales are likely to have similar values. More evidence is still needed to verify this hypothesis.

\section{REFERENCES}

[1] BuczKo U., Gerke H.H., HütTL R.F., Spatial distributions of lignite mine spoil properties for simulating 2-D variably saturated flow and transport, Ecological Engineering, 2001, 17(2), 103-114.

[2] Dmitruk S., Suchnicka H., Geotechniczne zabezpieczenie wydobycia, 1976.

[3] Fenton G.A., Griffiths D.V., Bearing-capacity prediction of spatially random c $\varphi$ soils, Canadian Geotechnical Journal, $2003,40(1), 54-65$.

[4] Fenton G.A., Vanmarcke E.H., Simulation of random fields via local average subdivision, Journal of Engineering Mechanics, 1990, 116(8), 1733-1749.

[5] Griffiths D.V., FenTON G.A., Bearing capacity of spatially random soil: the undrained clay Prandtl problem revisited, Geotechnique, 2001, 351-359

[6] KAwA M., ŁYDŻBA D., Evaluation of Bearing Capacity of Strip Footing Using Random Layers Concept, Studia Geotechnica et Mechanica, 2015, 37(3), 31-39.

[7] Lloret-CAвOt M., Fenton G.A., Hicks M.A., On the estimation of scale of fluctuation in geostatistics, Georisk: Assessment and Management of Risk for Engineered Systems and Geohazards, 2014, 8(2), 129-140.

[8] PieczyńsKa-KozŁowska J.M., Comparison Between Two Methods for Estimating the Vertical Scale of Fluctuation for Modeling Random Geotechnical Problems, Studia Geotechnica et Mechanica, 2015, 37(4), 95-103.

[9] RoBERTSON P.K., Soil behaviour type from the CPT: an update, 2nd International Symposium on Cone Penetration Testing, USA, 9-11 May 2010.

[10] ROBERTSON P.K., Soil classification using the cone penetration test, Canadian Geotechnical Journal, 1990, 27(1), 151-158.

[11] Uzielli M., Lacasse S., Nadim F., Phoon K.K., Soil variability analysis for geotechnical practice, Characterization and Engineering Properties of Natural Soils, 2006, 3, $1653-1752$

[12] Vanmarcke E., Random Fields: Analysis and Synthesis, MIT Press, 1983.

[13] Vessia G., Cherubini C., Pieczyńska J., PuŁa W., Application of random finite element method to bearing capacity design of strip footing, Journal of GeoEngineering, 2009, 4(3), 103-112. 